EDUCATION

\title{
What do we mean by the term "inflammation"? A contemporary basic science update for sports medicine
}

\author{
A Scott, K M Khan, C R Roberts, J L Cook, V Duronio
}

Br J Sports Med 2004;38:372-380. doi: 10.1136/bjsm.2004.011312

Most practicing sports medicine clinicians refer to the concept of "inflammation" many times a day when diagnosing and treating acute and overuse injuries. What is meant by this term? Is it a "good" or a "bad" process? The major advances in the understanding of inflammation in recent years are summarised, and some clinical implications of the contemporary model of inflammation are highlighted.

See end of article for authors' affiliations

Correspondence to: A Scott, University of British Columbia, 2633 Tennis Crescent

Vancouver V6T 2C1,

Canada; ascot!@

interchange.ubc.ca

Accepted 16 March 2004
D espite the widespread use of the term "inflammation" in sports medicine, clinicians and researchers rarely define precisely what they mean by it and whether or not it is a "good" or a "bad" process. ${ }^{1}$ Attendees at an IOC tendinopathies workshop in Athens (2003) concluded that both clinicians and scientists would benefit from a working definition of inflammation so that debate could have a rational foundation. As depicted in fig 1, inflammation is an umbrella term encompassing physical findings at four levels: clinical, physiological, cellular, and molecular. In a particular injury, some or all of the components may be present at one or more levels. Effective clinical reasoning and research require the ability to define which level is relevant. The purpose of this review is to share advances at the cellular and molecular levels of inflammation and to discuss how they may affect clinical management.

\section{INFLAMMATION: A COMPLEX INTERACTION OF CELLULAR SIGNALS AND RESPONSES}

Most clinicians were trained to think of the classic cellular inflammation model, ${ }^{2}$ but today any discussion of inflammation must involve consideration of the molecular level, and should also include the full range of cell types involved including platelets, endothelial cells, and peripheral neurones. Thus, we pay particular attention to the mechanisms of interaction among nine cell types that participate in the acute and chronic injury response (fig 2 ). In this model, the positive or negative outcome of injury is influenced by the simultaneous responses and interactions of numerous cell types. We hope the figures will facilitate the integration of data reviewed herein, and to develop a context in which to understand emerging treatments for musculoskeletal disorders. We have highlighted examples from sports medicine, and will not attempt to cover inflammation as it pertains to immune related disorders.
We will begin with the cells that predominate in the early phase of classical inflammation after an acute injury such as an ankle sprain (platelets, endothelial cells, neutrophils) through to healing in the later phases (macrophages, lymphocytes, fibroblasts). This is followed by an update on research into neurogenic inflammation, which is increasingly implicated in the development of repetitive strain injuries. ${ }^{3}$ We will not review the effects of inflammatory mediators on parenchymal cells that participate in tissue regeneration-for example, skeletal muscle satellite cells, pluripotent periosteal cells.

\section{Platelets}

Platelets have a deceptively simple appearance on standard blood smears. Despite their featureless, anuclear appearance and their origin as fragments of bone marrow megakaryocytes, platelets are fully functioning, complex coordinators of coagulation, inflammation, and repair. They store and dynamically express a repertoire of membrane bound and secreted products that are involved in pain, primary haemostasis, recruitment of white blood cells, and regulation of vascular tone, repair, and neovascularisation. ${ }^{4}$

Platelets are influenced by signals from the extracellular matrix as well as by those released from various cell types. After the initial trauma to the vasculature-for example, muscle strain or haematoma-circulating platelets contact collagens in the vessel walls (including types I, III, and VI). Specific receptors on the platelet surface, including the integrin $\alpha_{2 b} \beta_{3}$ and glycoprotein Ib-IX-V receptors, bind to collagen and trigger platelet adhesion and activation. ${ }^{5}$ These platelets then reorganise their cytoskeleton to form procoagulative spines, and release ADP and serotonin, which recruit further platelets and promote the accumulation of a platelet plug stabilised by strands of fibrin. ${ }^{4}$ Activated platelets synthesise and release an arachidonic acid metabolite, thromboxane A2, which mediates a second wave of platelet activation and aggregation by activating $G$ protein coupled receptors on the platelet membrane. ${ }^{6}$ The aggregation of platelets in the thrombus is mediated by

Abbreviations: bFGF, basic fibroblast growth factor; CGRP, calcitonin gene related peptide; COX, cyclooxygenase; EGF, endothelial growth factor; IL, interleukin; MCP, monocyte chemoattractant protein; MMP, matrix metalloproteinase; NGF, nerve growth factor; NSAID, non-steroidal anti-inflammatory drug; PDGF, platelet derived growth factor; PG, prostaglandin; $S P$, substance $P ; T G F$, transforming growth factor; TNF, tumour necrosis factor; VEGF, vascular endothelial growth factor 


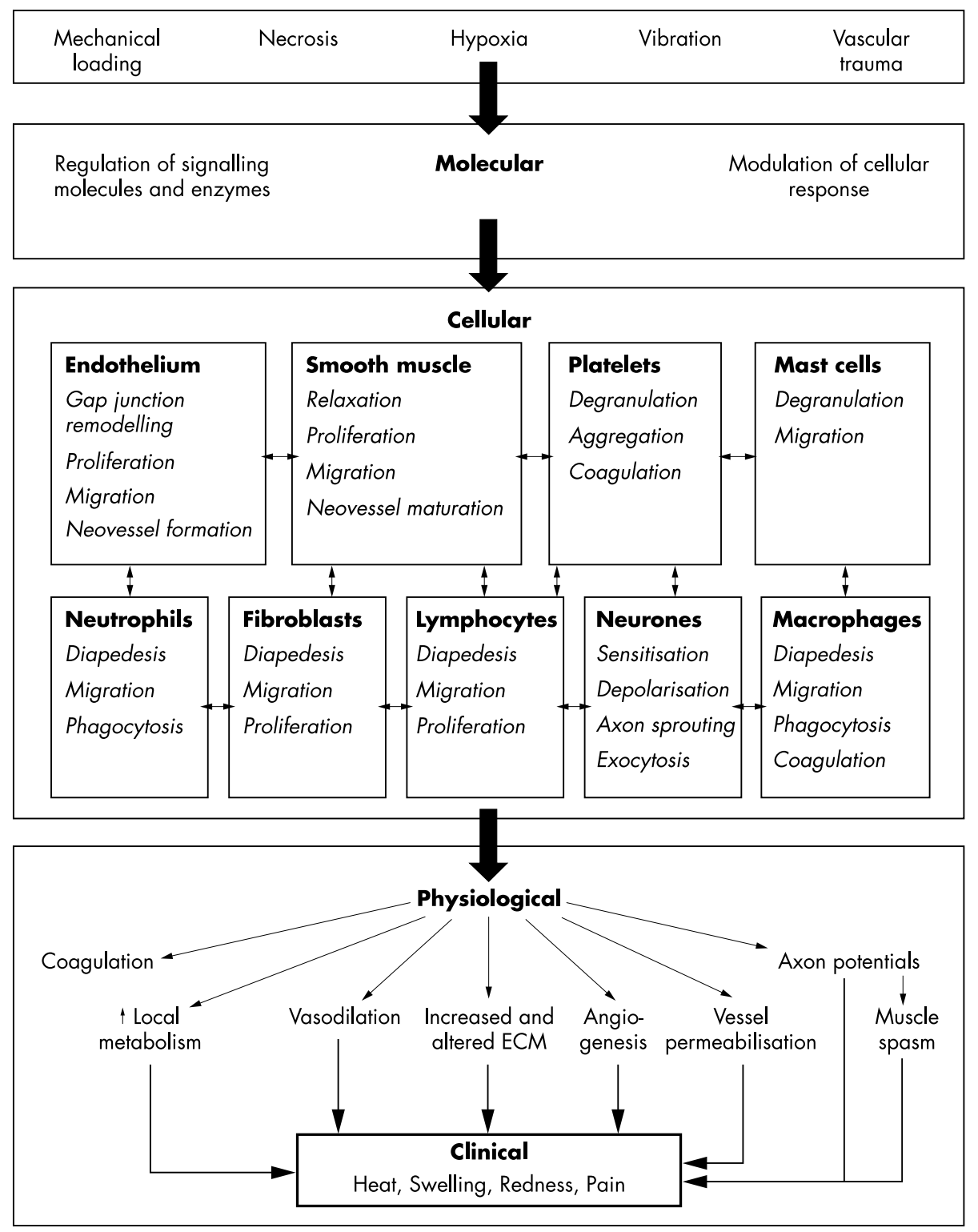

Figure 1 Inflammation is an umbrella term encompassing physical findings at four levels: clinical, physiological, cellular, molecular. Effective clinical reasoning and research require the ability to define which level is relevant. ECM, Extracellular matrix.

von Willebrand's factor, a glycoprotein released by activated platelets and endothelium. The endothelium can also negatively influence platelet function by releasing prostaglandins $\left(\mathrm{PGI}_{2}\right.$ and $\left.\mathrm{PGE}_{2}\right)$ and nitric oxide $(\mathrm{NO})$, which are vasodilatory and have an inhibitory effect on platelets, thereby preventing uncontrolled thrombosis. ${ }^{67}$

Platelets release factors that are crucial in influencing other cells to repair tissue. These factors include transforming growth factor $\beta$ (TGF $\beta$ ), platelet derived growth factor (PDGF), and endothelial growth factor (EGF). TGF $\beta$ binds to specific receptors (TGF $\beta R 1$, TGF $\beta R 2$, TGF $\beta$ R3) on numerous cell types to enhance or inhibit many physiological functions as well as inflammatory and reparative processes. Although TGF $\beta$ inhibits the production of chemotactic mediators including interleukin (IL) 1 and tumour necrosis factor (TNF) $\alpha,{ }^{8}$ it is itself moderately chemotactic for monocytes, T lymphocytes, and fibroblasts, but not neutrophils. ${ }^{90}$ When administered to healing injuries, TGF $\beta$ causes fibroblast proliferation, matrix secretion, and improved biomechanical function. ${ }^{11}{ }^{12}$ PDGF and EGF are potent stimulators of mitosis in most mesenchymal cell types, particularly smooth muscle cells, enhancing proliferation and angiogenesis. PDGF accelerates wound healing when applied topically, especially in combination with EGF. ${ }^{13}$ Research into the use of PDGFs to improve healing of acute tendon injuries in animal models ${ }^{14}$ generally found a short term, but not persistent, benefit in biomechanical outcome. Small scale clinical trials for tendinopathies using protein rich autologous plasma are now underway. ${ }^{15}$

\section{Endothelium}

Another cell type that is activated during the inflammation and repair of acute injuries is the endothelium. In the initial stages, endothelial cells regulate pain, coagulation, vascular tone, and the recruitment and passage of inflammatory cells. In addition, they are exposed to factors released early on by platelets, and later by macrophages, fibroblasts, lymphocytes, and neurones, which can induce endothelial cells to proliferate and remodel their surrounding extracellular matrix, eventually forming an expanded network of vessels 


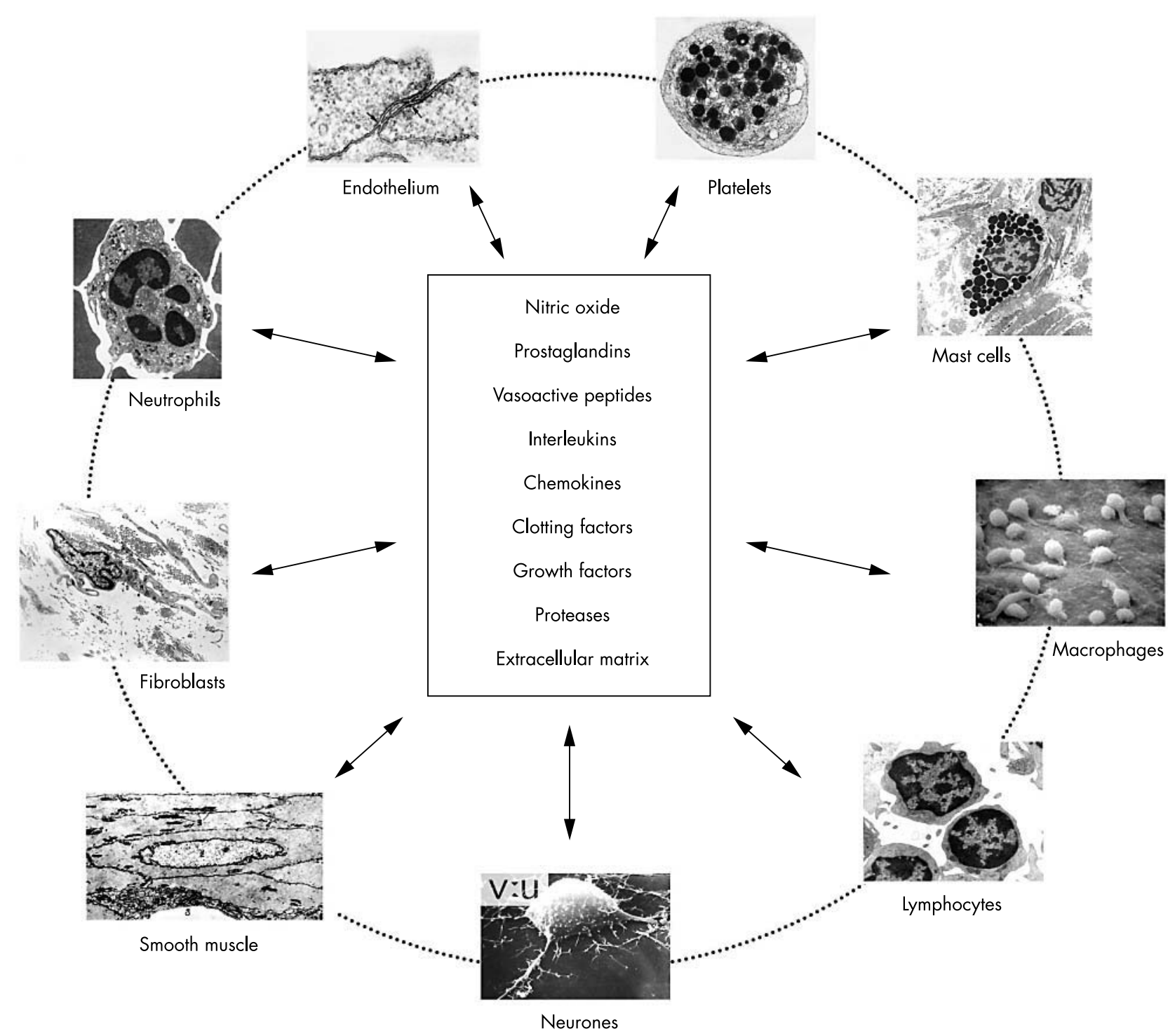

Figure 2 The evolving response of each cell to an injury depends on the integration of molecular signals originating from neighbouring cells and the extracellular environment.

to supply the early scar or "granulation" tissue. Neovessels gradually disappear from scar tissue by undergoing programmed cell death (apoptosis). ${ }^{16}$

Normally, endothelial cells generate anticoagulative signals including thrombomodulin, tissue factor pathway inhibitor, and ADPase. ${ }^{4}$ After injury, endothelial cells can respond to proinflammatory signals, thereby switching their role to one of enhancing coagulation-for example, by upregulating their expression of tissue factor. ${ }^{17}$ After coagulation, platelets can then signal endothelial cells to recruit white blood cells. Activated platelets express the CD40 ligand on their surface, which binds to the CD40 endothelial receptor, leading to increased endothelial expression of molecules that recruit adhesive leucocytes, including E-selectin, vascular cell adhesion molecule-1, IL8, and monocyte chemoattractant protein (MCP1). ${ }^{18} 19$ E-selectin, expressed on the luminal surface of activated endothelial cells, participates in the recruitment of leucocytes by slowing their transit time through the small vessels. ${ }^{20}$ This slowing of transit time allows subsequent firm (integrin dependent) adhesion of leucocytes to the endothelial surface. ${ }^{21}$ In addition to being modulated by platelets, endothelial cells may be induced by thrombin to produce raised concentrations of $\mathrm{NO}$ and prostaglandins, as well as chemokines such as IL8. IL8 interacts with the CXCR2 receptor on neutrophils, causing them to migrate toward the source of IL8. ${ }^{22}$

Endothelial cells can express and respond to a network of inflammatory mediators known as interleukins. Many cells (including platelets, neutrophils, monocytes, macrophages, lymphocytes, fibroblasts) are capable of releasing interleukins and thereby amplifying a variety of inflammatory and reparative processes. ILI is considered a prototypical inflammatory mediator, because of the vast array of inflammatory processes that it mediates, including synthesis of prostaglandin and NO. In response to ILl paracrine or autocrine stimulation, endothelial cells upregulate their expression of chemokines ${ }^{23}$ and adhesion molecules, ${ }^{24}$ resulting in increased recruitment of blood borne inflammatory cells. ILl also induces matrix metalloproteinase (MMP) expression in fibroblasts, which facilitates matrix degradation and inflammatory cell penetration. ${ }^{25}$ In contrast with IL1, IL6 is a prototypical "pleiotropic" mediator. Like TGF $\beta$, it is both 
proinflammatory and anti-inflammatory and regulates a variety of cellular functions. ${ }^{26}$ Another major proinflammatory signal, $\mathrm{TNF} \alpha$, is released by endothelial cells and activated macrophages, and overlaps many of the functions of ILl. ${ }^{26}$ After local trauma, interleukins have their greatest influence locally - that is, paracrine or autocrine, rather than endocrine-by binding to specific receptors on endothelium and on other nearby cells. However, after sufficient traumafor example, injurious eccentric loading of the quadricepsraised IL6 is found in the bloodstream ${ }^{27}$ and may influence distant cells and tissues, causing more widespread responses, such as increased production and release of blood cells from the bone marrow. ${ }^{28}$

The normal phases of angiogenesis after injury include initiation of the angiogenic response, remodelling of the extracellular matrix, proliferation and migration, maturation, and regression, each phase being governed by a different array of secreted and extracellular matrix signals. ${ }^{29}$ Early on, heparinase released by platelets may liberate the angiogenic factor basic fibroblast growth factor (bFGF) from the extracellular matrix, favouring its binding to the high affinity FGF receptors on endothelium and fibroblasts. ${ }^{30}$ Vascular endothelial growth factor (VEGF) is a potent angiogenic factor which is secreted in higher amounts later in the reparative stage by diverse cell types, especially macrophages. VEGF and its receptors are also upregulated under hypoxic conditions. ${ }^{29} 31$

The role of the endothelium in tendinosis is now receiving greater attention because of new evidence by Ohberg and Alfredson ${ }^{32}$ that associates neovascularisation with the development of a chronically painful tendon lesion. Biopsies of tendinosis do occasionally display areas of perivascular inflammatory cell invasion, indicating that the endothelium may have become activated at an earlier period, but this has not been confirmed. Animal overuse models suggest that neurovascular ingrowth is a late appearing feature of tendinosis. ${ }^{33}$

\section{Neutrophils}

Neutrophils are traditionally viewed as the "smart bomb" of inflammation. Highly destructive, they appear to operate on the uncritical assumption that any injury must be infected. Their main functions are phagocytosis and the killing of bacteria. The bactericidal toxicity of neutrophils results from their ability to release high levels of reactive oxygen species including hypochlorite, superoxide, and hydroxyl radicals. ${ }^{34}$ These reactive oxygen species are, however, non-specifically toxic, so in addition to killing bacteria that may or may not be present, they destroy surrounding injured or healthy cells. In a mouse wound model, neutrophil depletion resulted in faster repair, with no adverse effect on strength. ${ }^{35}$ Neutrophils undergo apoptosis and expose phosphatidylserine on their outer leaflet, marking themselves for phagocytosis by macrophages which arrive later at the site of injury.

Neutrophils, the first line of phagocytes in injured tissues, appear after a few hours, and account for the majority of cells present by 24 hours. ${ }^{36}$ Initially, they are released passively along with platelets from the injured vessels. Activated platelets then release a chemokine precursor, platelet basic protein, which is processed by neighbouring neutrophils to neutrophil activating protein 2 . The latter rapidly (within minutes) attracts neutrophils by its affinity for their CXCR2 receptor. ${ }^{36}{ }^{37}$ Because neutrophil activating protein 2 is chemotactic for neutrophils but not for macrophages, its early presence may explain neutrophil predominance in early inflammation. ${ }^{36}$

Neutrophils express powerful enzymes to support their roles in tissue debridement and clot resorption. These enzymes belong to one of two families, the MMPs and the serine proteinases. Serine proteinases include cathepsin G, proteinase 3, and urokinase-type plasminogen activator. Among its many substrates, urokinase-type plasminogen activator converts plasminogen into plasmin, which can degrade the fibrinous clot-an essential stage of healing. The MMPs released by activated neutrophils include MMP8 (neutrophil collagenase) and MMP9 (gelatinase B). Together these two enzymes can degrade most components of the extracellular matrix: elastin, fibrin, fibronectin, laminin, vitronectin, collagens, and proteoglycans. After tendon injury (rat flexor tendon laceration), early MMP9 activity appears to play a predominant role in collagen denaturation, rather than collagen remodelling, which was still occurring at day $28 .^{38}$

\section{"The absence of neutrophils in chronic tendinopathies has led researchers and clinicians to question the inflammatory basis of so called tendinitis"}

Because neutrophils are not required for the successful repair of sterile injuries, ${ }^{39}$ reducing their recruitment into injured areas during the initial hours after injury is a reasonable therapeutic goal. In particular, neutrophils appear to play a predominantly negative role in acute exercise associated injury. ${ }^{1}$ A new line of research is to target the damaging aspects of neutrophil function, specifically their excessive free radical production. ${ }^{1}$ The absence of neutrophils in chronic tendinopathies has led researchers and clinicians to question the inflammatory basis of so called "tendinitis". ${ }^{40}$

\section{Monocytes and macrophages}

Macrophages and monocytes are more predominant during the later stages of inflammation repair; by $24-48$ hours they are the most prominent cell type, along with lymphocytes by day $5 .{ }^{36}$ Macrophages represent a diverse cell population in injured tissues, originating from the proliferation of resident macrophages (including various differentiated types: osteoclasts, type A synovial cells, Kupffer cells, etc) or the invasion and differentiation of peripheral blood monocytes. Macrophages are recruited to injured sites by chemokines-for example, MCPl-which are released by activated endothelium and fibroblasts. ${ }^{41}$ Macrophages are activated by many signals, including TNF $\alpha$ and ILl, as well as by conditions in the injured tissue such as hypoxia. ${ }^{42}$ They are very versatile cells, with the ability to secrete more than 100 different products, including the bulk of the major proinflammatory mediators $\left(\mathrm{PGE}_{2}, \mathrm{TNF} \alpha, \mathrm{ILl}\right)$, thereby creating a positive feedback loop to amplify their response. Activated monocytes play an early role in coagulation, expressing tissue factor VII and prothrombinase on their surface. ${ }^{43}$ They are involved in phagocytosis and extracellular matrix destruction through the activity of MMPs $(1,3,9,10,12)$, but also secrete a broad spectrum of growth factors required for repair, including both proangiogenic-for example, bFGF, VEGF-and antiangiogenic-for example, interferon $\alpha$, thrombospondin 1 -factors. ${ }^{44}$ MMP3 is able to cleave decorin and thereby liberate bound stores of TGF $\beta$ from the extracellular matrix, ${ }^{45}$ providing a profibrotic stimulus to fibroblasts. In addition to their major role in directing repair, macrophages also secrete factors required for tissue regeneration. ${ }^{46}$

Macrophages are prominent during the acute and chronic stages of many injuries common in sports, including those affecting ligament, bursa, synovium, muscle, and intervertebral disc. ${ }^{47-51}$ In tendons, macrophages are present during the acute stage of tendon injury, and can be observed actively phagocytosing collagenous and cellular debris. ${ }^{52}$ However, they are quite scarce in surgical biopsies of tendinosis and even tendon rupture. ${ }^{53}$

\section{T lymphocytes}

$\mathrm{T}$ lymphocytes are predominant in the remodelling phase of injury. ${ }^{54}$ By 14 days, they are the most prominent cell type in 
wounds.$^{36}$ Like fibroblasts, $\mathrm{T}$ lymphocytes proliferate in response to ILl..$^{55} \mathrm{~T}$ lymphocytes are recruited to injured areas primarily by interferon $\gamma$ inducible protein 10 and monokine induced by interferon $\gamma$ (Mig), which are both secreted by macrophages and which bind to the T lymphocyte CXCR receptors. $^{56} \mathrm{~T}$ lymphocytes are capable of producing and exporting the potent angiogenic and fibrogenic factor, bFGF. ${ }^{57}$ Depletion of $\mathrm{T}$ lymphocytes delays healing, reduces collagen secretion, and results in more fragile scar tissue. ${ }^{58} 59$ Treatments that impair or deplete $\mathrm{T}$ lymphocytes include corticosteroids and cyclosporin, which delay and inhibit wound healing. ${ }^{60}$ Like macrophages, T lymphocytes are present in most injured soft tissues. They are particularly prominent in bursal biopsies in patients with chronic rotator cuff pathology, in which synovial and vascular hyperplasia are prominent. ${ }^{47}$

\section{Fibroblasts}

The proliferation of fibroblasts and the secretion of increased amounts of provisional matrix and scar tissue are hallmarks of the later repair processes. Fibroblasts migrate into the fibrin clot that is created in areas of extravasation in inflammation, and these fibroblasts synthesise a versican and hyaluronan rich matrix. ${ }^{60 a}$ Fibroblast activation in the area of the former clot may be partially attributable to the activity of clot associated proteinases, including plasmin, through the proteinase activated receptor system. A number of chemokines and growth factors are probably localised to provisional matrix by their affinity for glycosaminoglycans, and these include MCP-3, SDF-1, connective tissue growth factor, and IL8, and it is in the provisional matrix that myofibroblasts express the gene for type I collagen and begin the process of structural repair. The degree to which increased tissue turgor in inflammation and repair is attributable to proteoglycan-bound water is unknown. Fibroblasts proliferate in response to many signals-for example, IL1, IL4, IL6, TNF $\alpha$, insulin-like growth factor I, PDGF, TGF $\beta$, EGF, nerve growth factor (NGF) - that are released by platelets, endothelial cells, mast cells, macrophages, and other fibroblasts. The later stages of inflammation, in particular, are characterised by the local proliferation of collagen-secreting fibroblasts and their contractile offspring, the myofibroblast. ${ }^{16}$ However, it is now apparent that a portion of the increased fibroblast population may enter injured areas from the circulation very early on in the inflammatory process (within hours). ${ }^{61}$ Myofibroblasts differentiate from both tissue fibroblasts and peripheral blood fibrocytes in response to TGF $\beta$, and may be identified by their expression of smooth muscle-type actin, which allows them to exert a contractile force in healing tissues. Myofibroblasts typically disappear from wounds by apoptosis, ${ }^{16}$ and this appears concomitant with degradation of the provisional matrix. ${ }^{61 a}$

Fibroblasts can secrete inflammatory mediators in response to mechanical loading. For example, tenocytes and ligament cells subjected to stretching forces, in vitro, increase their synthesis or release of $\mathrm{PGE}_{2} \cdot{ }^{62}$ Initially, this line of evidence pointed to a possible alternative way of activating aspects of the inflammatory response, bypassing coagulation and platelet activation entirely. It seemed plausible that continuous mechanical loading of fibroblast populated tissues such as tendons may lead to a "pseudo-inflammatory" autocrine and paracrine response, thereby triggering degradation of the extracellular matrix, proliferation, or even angiogenesis, all in the absence of white blood cell infiltration or vascular trauma. Recent work, however, has shown that tensile loading of human patellar tendon fibroblasts in vitro leads to downregulation of the major inflammatory cytokines, including ILl, TNF $\alpha$ and TGF $\beta$ at the mRNA level. ${ }^{63}$ In addition, tensile loading of tenocytes cultured in three dimensional collagen inhibits the ability of ILl to induce
MMP3 expression. ${ }^{64}$ A moderate increase in the level of PGE2 has been detected in the peritendinous space after normal, non-painful exercise in healthy athletes, but a specific role in tendon collagen metabolism in this situation is not yet clear. ${ }^{65}$

\section{Mast cells}

Like tissue macrophages, mast cells are relatively long living resident cells derived from haemopoietic precursors. They are capable of activating, migrating, proliferating, and influencing various inflammatory and reparative processes. Mast cells have been likened to the security alarms of inflammation. Once activated (by antigens through their IgE $\mathrm{F}_{\mathrm{C}}$ receptors, or by vibration, hypoxia, thrombin, cytokines, or neuropeptides), they quickly respond by degranulating and thereby (a) activating nearby cells and (b) stimulating neuropeptide-containing sensory nerves to generate a regional neurogenic inflammation through an axonal reflex. ${ }^{66}$

The best characterised, early function of mast cells after injury is the thrombin induced, histamine mediated increase in vascular permeability, with increased oedema and fibrin deposition. When mast cells degranulate, they release tryptase which, with thrombin, activates the protease activated receptor 2 on other mast cells, as well as on sensory neurones. ${ }^{67} 68$ This activation of mast cells by thrombin or tryptase results in further degranulation, contributing to a cascade of mast cell activation. ${ }^{67}$

In addition to their early roles, mast cells play increasingly recognised roles throughout inflammation and repair, ${ }^{69} 70$ being capable of secreting a broad range of reparative mediators and enzymes including $\mathrm{TNF} \alpha{ }^{71}{ }^{7 L} 4,{ }^{41}$ IL6, bFGF, ${ }^{70}$ TGF $\beta{ }^{71}$ PDGF, tryptase, and MMP9. ${ }^{72}$ Mast cells are recruited to sites of injury in increasing numbers (up to fivefold) by MCP1, ${ }^{41}$ where they are activated by hypoxia ${ }^{73}$ or inflammatory mediators such as $\mathrm{PGE}_{2}$ or TNF $\alpha .{ }^{72}{ }^{74}$ Among the many mast cell products, $\mathrm{NGF}^{75}$ is interesting given the close anatomical association between mast cells and sensory nerve endings, ${ }^{37677}$ and the ability of NGF to cause pain ${ }^{78}$ and axonal sprouting. ${ }^{79}$ Mast cells also accumulate near sites of angiogenesis, for example after tendon rupture. ${ }^{80}$ Most of their angiogenic capacity has been attributed to tryptase, which can directly induce endothelial cells to proliferate, migrate, and align into nascent capillary tubes. ${ }^{81}$ Because abnormal nerve and vessel growth into herniated discs has been observed in cases of chronic low back pain, ${ }^{82} 83$ it has been hypothesised that the mast cell may be responsible. ${ }^{84}$

\section{Neurones}

Peripheral nerve cells can influence all of the above inflammatory cell types. ${ }^{66}$ Many of their effects are mediated by vasoactive neuropeptides. The two best known of these, substance P (SP) and calcitonin gene related peptide (CGRP), are synthesised in the dorsal root ganglia within the cell bodies of pain sensitive neurones (small myelinated (A $\delta$; type III) or large unmyelinated (C; type IV)). After synthesis, these neuropeptides are transported to the axon terminals where they are stored in vesicles. Several factors and enzymes that are present in injured tissues contribute to the release of SP and CGRP, including mast cell tryptase and bradykinin..$^{85} 86$

SP is emerging as a central player in neurogenic inflammation and repair. It can activate NKl receptors on endothelial cells, causing $(a)$ increased production of $\mathrm{NO}^{87}$ and $(b)$ angiogenesis. ${ }^{88}$ SP can enhance inflammatory cell recruitment by upregulating P-selectin on endothelial cells and by chemoattracting neutrophils and macrophages. ${ }^{89-91}$ In macrophages, SP stimulates the production of arachidonic acid, IL1, and IL6. ${ }^{66} \mathrm{SP}$ also stimulates lymphocytes and fibroblasts to proliferate. ${ }^{66}{ }^{92}$ Mast cells respond to SP (and CGRP) by degranulating. ${ }^{93}$ The importance of SP in tendon and ligament healing is highlighted by the fact that denervation results in delayed healing, ${ }^{89}$ whereas normal injured tissues 
are characterised by increased numbers of SP-containing neurones during the first few weeks of healing. ${ }^{94} 95$

INFLAMMATION: A DIAGNOSTIC DILEMMA

To provide an interim summary, we emphasise that the concept "inflammation" encompasses an extraordinary complexity of cellular responses. For clarity we described the cell types involved in turn (from the early injury process to its later stages), but the biological reality is that the cells are present in various combinations. Thus, in any one clinical scenario, particular mediators and cell types may play greater or lesser roles. Dogma has suggested that the level of pain correlates highly with the underlying presence of inflammatory cells, ${ }^{96}$ but this diagnostic relation has not been borne out by biopsy or biochemical studies, particularly in chronic musculoskeletal disorders. There is not always an obvious link between inflammation visible under the microscope or measured biochemically on the one hand and that clinically apparent and characterised by the original cardinal signs on the other. Thus the clinical "diagnosis" of inflammation is insufficient rationale for treatment.

\section{MEASUREMENT OF INFLAMMATION IN CLINICAL RESEARCH}

In clinical research, measuring inflammation has generally relied on subjective scales addressing pain, swelling, redness or on gross functional measures and volumetric measures of swelling. ${ }^{97}$ It is very difficult for clinical researchers to determine the roles of specific cellular processes in clinical populations. Biopsy tissue is rarely available in most conservatively managed patients, and measurement of cytokines in blood and urine is limited because it is virtually impossible to identify the main sources and targets of the measured mediator. An interesting approach is to radiolabel white blood cell populations before exercise so that white blood cell accumulation can be detected radiologically in injured tissues. ${ }^{27}$ This approach confirmed the presence of neutrophils in human skeletal muscle after eccentric exercise, but low sensitivity and expense limits its usefulness in clinical research. Another approach has been to insert fine microdialysis catheters directly into the tissue of interest. ${ }^{98-100}$ This more sensitive but invasive technique offers the exciting possibility of detecting mediators of pain, inflammation, and repair in vivo. It has been used to show a lack of raised $\mathrm{PGE}_{2}$ concentration in the tendons of patients with chronic patellar, mid-portion Achilles, or extensor carpi radialis brevis tendinopathies. ${ }^{98-100}$ Perhaps future microdialysis studies will examine other mediators and other challenging pain syndromes of unknown pathophysiology.

\section{IMPACT OF THE CONTEMPORARY MODEL ON CURRENT ANTI-INFLAMMATORY TREATMENTS}

In this section we discuss current treatment options in the light of the data reviewed above. This remains a challenging area in which the indications and expected benefits are far from evidence based in many cases.

\section{Non-steroidal anti-inflammatory drugs (NSAIDS) and cyclooxygenase (COX) inhibitors}

NSAIDs have been in use in various forms for more than 3500 years, and remain one of the most popular classes of drugs today. Each year about 120 billion aspirin tablets are consumed world wide, ${ }^{101}$ and, in older people, contribute to an estimated 100000 hospital admissions and 16500 deaths each year from NSAID related complications of the gastrointestinal tract. ${ }^{102}$ Clearly, the use of NSAIDs must be carefully justified.

NSAIDs are a diverse group of compounds that share the property of being able to inhibit one or more isoforms of
COX. ${ }^{102} \mathrm{COX}$ is one of two enzymes that degrades arachidonic acid (the other is lipoxygenase). Currently there are three known isoforms: COX1, COX2, and COX3. COX catalyzes the rate limiting step in the formation of prostaglandins and thromboxane. COXI has traditionally been considered the constitutively expressed, "housekeeping" isoform, responsible for maintenance of gastrointestinal viability and platelet aggregation. However, COX2 is now known also to be constitutively expressed in the spinal cord. ${ }^{102}$ COX2, in contrast with COX1, is usually considered the inducible form of the enzyme. Activation of inflammatory cells, especially macrophages, results in upregulation of COX2 expression with a corresponding increase in prostaglandins and thromboxanes. Most NSAIDs inhibit COX1 and COX2 equally. ${ }^{103} 104$ This lack of specificity for the COX1 and COX2 isoforms is thought to account for the high level of gastrointestinal related problems from long term NSAID use. ${ }^{103} 104$ NSAIDs also decrease clotting ability, as all of the thromboxane synthesised by platelets is produced by COXI. Clinicians must remember that NSAIDs may alleviate pain directly, not only by reducing peripheral levels of proinflammatory mediators. ${ }^{105}$ They can reduce concentrations of prostaglandins in the central nervous system, in addition to limiting pain peripherally by reducing the ability of prostaglandins to sensitise nerves - that is, lower their threshold to painful stimulus. ${ }^{102} \mathrm{COX} 3$ is abundantly expressed in the central nervous system and is a preferential target of acetaminophen, which may explain why acetaminophen is less able to reduce peripheral inflammation. ${ }^{106} \mathrm{COX} 3$ activity is also inhibited by aspirin, diclofenac, and ibuprofen. ${ }^{106}$

NSAIDS and specific COX2 inhibitors are commonly used to treat many acute soft tissue injuries. Whether NSAIDs and COX inhibitors affect tissue healing positively or negatively is a very important question for clinicians to examine. Understanding the complexity and breadth of inflammation reinforces that NSAIDs do not influence a single pathway or cell type. It may be most appropriate to reserve prescription for those conditions in which they have been shown to be effective, rather than assume naively that "inflammation" is a problem and that an "anti-inflammatory" drug is the solution. Unfortunately for patients and doctors, most NSAID trials for soft tissue healing have reported no significant differences in long term outcomes. ${ }^{97}$ Some laboratory studies have detected small positive ${ }^{107}$ or negative ${ }^{108}{ }^{109}$ differences in the restoration of tissue function (surrogate outcome measures). Dahners et al ${ }^{107}$ found that collagen synthesis and mechanical strength in healing ligaments was improved during piroxicam treatment, although the outcome was the same as in the controls. Specific COX2 inhibitors now on the market may avoid the side effects of COXI inhibition, and have been validated in acutely injured and surgical sports medicine populations. ${ }^{110}$ Stovitz and Johnson ${ }^{110}$ have pointed out several potential problems associated with prescribing NSAIDS in various sports medicine conditions.

\section{Corticosteroids}

Corticosteroids have been used for many years with the aim of treating sport induced inflammation. ${ }^{111}$ They exert their inhibitory effects by binding to intracellular receptors found in most cell types of the body. The corticosteroid-receptor complex translocates to the nucleus and alters (usually suppresses) transcriptional activity-for example, suppressing $\mathrm{COX}_{2}{ }^{112}$ and collagen synthesis. ${ }^{113}$ This suppresses the production of most cytokines and inflammatory cell function. ${ }^{114}$ Neurogenic inflammation may be affected by the ability of corticosteroids to prevent the upregulation of CGRP mRNA. ${ }^{115}$ An inhibitor of phospholipase, lipocortin, is upregulated in cells exposed to corticosteroids, blocking the release of arachidonic acid from the cell membrane. ${ }^{112}$ The 
serious side effects of corticosteroids, including tendon rupture and cartilage degeneration, were recognised a few years after they first came into use in the 1950s. Judicious use of corticosteroids has been reported anecdotally to accelerate recovery of acute hamstring strains, with no reported side effects or functional deficits. ${ }^{116}$ This review highlights that the multifactorial nature of inflammation should warn against oversimplifying the role of corticosteroids. Clinical treatment should rely on studies that show clinically relevant outcomes, rather than attributing likelihood of success to assumptions that there is a biological rationale for their effectiveness.

\section{Physical modalities}

Various modalities have been ostensibly to "reduce inflammation" over the years. Is there evidence to support these claims? Ice is widely used in sports medicine. When used directly after injury, its beneficial effects are thought to result from the slowing of metabolism in cooled tissues with a resultant decrease in secondary, hypoxic injury. Given the contemporary model of inflammation proposed here, tissue cooling may also have numerous other effects on cellular outcomes.

Other physical modalities are less well established. Although ultrasound treatment has no documented antiinflammatory action, ${ }^{117}$ it causes fibroblast proliferation in injured skeletal muscle ${ }^{118}$ and enhances angiogenesis and bone deposition in healing fractures. ${ }^{119}$ These effects may be due in part to the increased expression of PDGF by endothelium and osteoblasts subjected to ultrasound. ${ }^{120}$ Therapeutic laser inhibits inflammation, although problems in standardising the dosage of laser delivered make any interpretation of this literature very difficult. Low level laser treatment decreased $\mathrm{PGE}_{2}$ concentrations by inhibiting $\mathrm{COX} 2$ in cell cultures. ${ }^{121}$ In the rat paw model of carageenan induced inflammation, laser treatment inhibited oedema formation but less effectively than indomethacin. ${ }^{122}$ In patients with tennis elbow, a double blind, randomised controlled trial of low level laser produced a small improvement in pain and improved grip strength after eight treatments, but the authors concluded that laser alone was not a recommended treatment. ${ }^{123}$ High voltage pulsed current is widely used in many sports medicine clinics to decrease post-traumatic oedema, although no clinical trials in sports medicine populations exist to our knowledge. There are promising reports that this treatment can reduce chronic hand oedema in patients with repetitive wrist injuries ${ }^{124}{ }^{125}$ and chronic effusions in patients with osteoarthritis of the knee, ${ }^{126}$ in line with the findings from animal models of reduced inflammatory oedema and protein extravasation after this treatment. ${ }^{127-129}$ These data suggest that clinicians may need to limit claims about the effectiveness of modalities to those settings in which randomised controlled trials have shown clinical

\section{What is already known}

A large body of preclinical data on inflammation which has not previously been reviewed for the sports medicine reader is summarised. This is followed by a critical examination of mechanisms for established and emerging treatments of soft tissue sports injuries.

What this study adds

This paper is intended as a tutorial and update on inflammation, a concept used many times daily loften uncritically) by sports medicine practitioners. We present a contemporary of inflammation as a complex cascade of molecular and cellular events. We hope our model will be thought provoking for journal readers. effectiveness. Speculating that the mechanisms may be due to "reducing inflammation" would be criticised by methodologists as generalising beyond the available evidence.

\section{PERSPECTIVE AND NEW TREATMENT HORIZONS}

This review has emphasised the complexity of inflammation, and has presented a model in which cells mount an integrated response to injury, modifying their behaviour according to their interactions with neighbouring cells and their extracellular environment. However, this molecular system is far from perfect. Cell types with divergent goals can, in their zeal to efficiently sterilise and patch up an injured area, interfere with one another's programmes-and thereby compromise the overall goal of restoring a perfectly healed structure. For example, the extraordinary repertoire of macrophages and their essential role in coordinating repair is in dramatic contrast with the highly destructive neutrophil. ${ }^{35}$ Current research seeks new treatments to inhibit neutrophil mediated tissue destruction. ${ }^{1}$ As another example, the propensity of fibroblasts to proliferate and quickly fill in a damaged area can often outpace the resident tissue cells' attempts at regeneration; this is particularly the case in skeletal muscle. ${ }^{130}$ Until recently, it was believed that fibroplasia provided an essential connective tissue scaffold for lengthening myotubes. ${ }^{131}$ However, a novel injection treatment (suramin) has been shown in preclinical studies to inhibit TGF $\beta$ and fibroblast proliferation, and thereby improve muscle regeneration. This study effectively shows that fibroblast proliferation and deposition of extracellular matrix in injured muscle is a dispensable feature of the inflammation repair response in this setting. ${ }^{132}$ These are both examples of research that is targeting specific cellular responses as opposed to the entire inflammation repair response. Other novel treatments on the horizon for musculoskeletal injuries include modulation of the concentrations of nitric oxide, ${ }^{133-136}$ a multifunctional mediator of pain, inflammation, and tissue repair.

In summary, we highlight that inflammation is a complex phenomenon that is gradually becoming unravelled. Our review emphasises that it would be a gross oversimplification for clinicians to assume that painful sports related conditions are always due to inflammation and will necessarily benefit from anti-inflammatory medication. The complexity of the interactions outlined underscores that it is impossible to speculate from first principles as to whether NSAIDs, corticosteroids, and other treatments influence tissue healing for better or worse. NSAIDs can produce short term pain relief by influencing central and peripheral pain pathways, and these effects should not necessarily be attributed to successful inhibition of other events encompassed by the term inflammation. On the other hand, NSAIDs may influence tissue healing in a variety of harmful or beneficial ways. This means that there is a need for trials of NSAIDs, corticosteroids, and physical modalities with clinically relevant outcomes such as return to function and long term recovery. As surprising as it may seem, there has not been an abundance of high quality, adequately powered randomised studies to provide the clinician with strong evidence about the role of these treatments in common conditions.

\section{Authors' affiliations}

A Scott, K M Khan, C R Roberts, V Duronio, University of British

Columbia, Vancouver, Canada

J L Cook, LaTrobe University, Melbourne, Australia

\section{REFERENCES}

1 Toumi H, Best TM. The inflammatory response: friend or enemy for muscle injury? Br J Sports Med 2003;37:284-6. 
2 Scott A, Khan KM, Cook JL, et al. What is "inflammation?" Are we ready to move beyond Celsus? Br J Sports Med 2004;38:248-9.

3 Hart DA, Frank CB, Bray RC. Inflammatory processes in repetitive motion and overuse syndromes: potential role of neurogenic mechanisms in tendons and ligaments. In: Fine $\amalg$, ed. Repetitive motion disorders of the upper extremity. Rosemont: American Academy of Orthopaedic Surgeons, 1995:247-62.

4 Marcus AJ. Platelets: their role in hemostasis, thrombosis and inflammation. In: Snyderman R, ed. Inflammation: basic principles and clinical correlates, 3rd ed. Philadelphia: Lipincott Williams \& Wilkins, 1999:77-95.

5 Naimushin YA, Mazurov AV. Role of glycoprotein Ilb-llla (alpha llb beta 3 integrin) in stimulation of secretion from platelet granules. Biochemistry (Mosc) 2003;68:209-16.

6 Wang GR, Zhu Y, Halushka PV, et al. Mechanism of platelet inhibition by nitric oxide: in vivo phosphorylation of thromboxane receptor by cyclic GMPdependent protein kinase. Proc Natl Acad Sci USA 1998;95:4888-93.

7 Ohman KP, Yun JC, Keiser HR. Interaction of prostaglandins with adenosine diphosphate induced increase in cytosolic free calcium in human platelets. Scand J Clin Lab Invest 1992;52:483-90.

8 Zissel G, Schlaak J, Schlaak $M$, et al. Regulation of cytokine release by alveolar macrophages treated with interleukin-4, interleukin-10, or transforming growth factor beta. Eur Cytokine Netw 1996;7:59-66.

9 Pierce GF, Mustoe TA, Lingelbach J, et al. Platelet-derived growth factor and transforming growth factor-beta enhance tissue repair activities by unique mechanisms. J Cell Biol 1989;109:429-40.

10 Adams DH, Hathaway M, Shaw J, et al. Transforming growth factor-beta induces human $\mathrm{T}$ lymphocyte migration in vitro. J Immunol 1991; 147:609-12.

11 Roberts AB, Sporn MB, Assoian RK, et al. Transforming growth factor type beta: rapid induction of fibrosis and angiogenesis in vivo and stimulation of collagen formation in vitro. Proc Natl Acad Sci USA 1986;83:4167-71.

12 Spindler KP, Murray MM, Detwiler KB, et al. The biomechanical response to doses of TGF-beta 2 in the healing rabbit medial collateral ligament. J Orthop Res 2003;21:245-9.

13 Gope R. The effect of epidermal growth factor \& platelet-derived growth factors on wound healing process. Indian J Med Res 2002;1 16:201-6.

14 Molloy T, Wang Y, Murrell G. The roles of growth factors in tendon and ligament healing. Sports Med 2003;33:381-94.

15 Almekinders LC, Banes AJ. A biologic approach to the treatment of tendinopathy. Paper presented at the IOC Workshop on Tendinopathies, Athens, Greece, 2003.

16 Desmouliere A, Redard M, Darby I, et al. Apoptosis mediates the decrease in cellularity during the transition between granulation tissue and scar. Am J Pathol 1995; 146:56-66.

17 Yang Y, Loscalzo J. Regulation of tissue factor expression in human microvas cular endothelial cells by nitric oxide. Circulation 2000;101:2144-8.

18 Karmann K, Hughes CC, Schechner J, et al. CD40 on human endothelial cells: inducibility by cytokines and functional regulation of adhesion molecule expression. Proc Natl Acad Sci USA 1995;92:4342-6.

19 Thienel U, Loike J, Yellin MJ. CD154 (CD4OL) induces human endothelial cell chemokine production and migration of leukocyte subsets. Cell Immunol 1999; 198:87-95.

20 Kunkel EJ, Ley K. Distinct phenotype of E-selectin-deficient mice. E-selectin is required for slow leukocyte rolling in vivo. Circ Res 1996;79:1 196-204.

21 Klintman D, Schramm R, Menger MD, et al. Leukocyte recruitment in hepatic injury: selectin-mediated leukocyte rolling is a prerequisite for CD18dependent firm adhesion. J Hepatol 2002;36:53-9.

22 Benelli R, Morini M, Carrozzino F, et al. Neutrophils as a key cellular target for angiostatin: implications for regulation of angiogenesis and inflammation. FASEB J 2002;16:267-9.

23 Volk T, Hensel M, Schuster H, et al. Secretion of MCP-1 and IL- 6 by cytokine stimulated production of reactive oxygen species in endothelial cells. Mol Cell Biochem 2000;206: 105-12

24 Raab M, Daxecker H, Markovic S, et al. Variation of adhesion molecule expression on human umbilical vein endothelial cells upon multiple cytokine application. Clin Chim Acta 2002;321:11-16.

25 Tsuzaki M, Guyton G, Garrett W, et al. IL-1 beta induces COX2, MMP-1, -3 and -13 , ADAMTS-4, IL-1 beta and IL- 6 in human tendon cells. J Orthop Res 2003;21:256-64.

26 Cavaillon JM. Pro- versus anti-inflammatory cytokines: myth or reality. Cell Mol Biol (Noisy-le-grand) 2001;47:695-702.

27 Macintyre DL, Sorichter S, Mair J, et al. Markers of inflammation and myofibrillar proteins following eccentric exercise in humans. Eur J Appl Physiol 2001;84:180-6.

28 Liu F, Poursine-Laurent J, Wu HY, et al. Interleukin-6 and the granulocyte colony-stimulating factor receptor are major independent regulators of granulopoiesis in vivo but are not required for lineage commitment or terminal differentiation. Blood 1997;90:2583-90.

29 Griffioen AW, Molema G. Angiogenesis: potentials for pharmacologic intervention in the treatment of cancer, cardiovascular diseases, and chronic inflammation. Pharmacol Rev 2000;52:237-68.

30 Vlodavsky I, Fuks Z, Ishai-Michaeli R, et al. Extracellular matrix-resident basic fibroblast growth factor: implication for the control of angiogenesis. J Cell Biochem 1991;45:167-76.

31 Howdieshell TR, Riegner C, Gupta V, et al. Normoxic wound fluid contains high levels of vascular endothelial growth factor. Ann Surg 1998;228:707-15.

32 Ohberg L, Alfredson H. Sclerosing therapy in chronic Achilles tendon insertional pain-results of a pilot study. Knee Surg Sports Traumatol Arthrosc 2003;12:12.

33 Gamer L, McDermott K, Cox K, et al. Molecular and cellualar analysis of rotator cuff tendinosis in a rat model. Paper presented at: 48th Annual Meeting of the Orthopaedic Research Society, 2002.
34 Bainton DF. Developmental biology of neutrophils and eosinophils. In: Snyderman R, ed. Inflammation: basic principles and clinical correlates, 3rd ed. Philadelphia: Lipincott Williams \& Wilkins, 1999:13-34.

35 Dovi JV, He LK, DiPietro LA. Accelerated wound closure in neutrophildepleted mice. J Leukoc Biol 2003;73:448-55.

36 Gillitzer R, Goebeler M. Chemokines in cutaneous wound healing. J Leukoc Biol 2001;69:513-21.

37 Proudfoot AE, Peitsch MC, Power CA, et al. Structure and bioactivity of recombinant human CTAP-III and NAP-2. J Protein Chem 1997;16:37-49.

38 Oshiro W, Lou J, Xing X, et al. Flexor tendon healing in the rat: a histologic and gene expression study. J Hand Surg [Am] 2003;28:814-23.

39 Simpson DM, Ross R. The neutrophilic leukocyte in wound repair a study with antineutrophil serum. J Clin Invest 1972;51:2009-23.

40 Khan KM, Cook JL, Kannus P, et al. Time to abandon the "tendinitis" myth. BMJ 2002;324:626-7.

41 Trautmann A, Toksoy A, Engelhardt E, et al. Mast cell involvement in normal human skin wound healing: expression of monocyte chemoattractant protein1 is correlated with recruitment of mast cells which synthesize interleukin- 4 in vivo. J Pathol 2000;190:100-6.

42 Hirani N, Antonicelli F, Strieter RM, et al. The regulation of interleukin-8 by hypoxia in human macrophages: a potential role in the pathogenesis of the acute respiratory distress syndrome (ARDS). Mol Med 2001;7:685-97.

43 Bokarewa MI, Morrissey JH, Tarkowski A. Tissue factor as a proinflammatory agent. Arthritis Res 2002;4:190-5.

44 Sunderkotter C, Goebeler M, Schulze-Osthoff K, et al. Macrophage-derived angiogenesis factors. Pharmacol Ther 1991;51:195-216.

45 Imai K, Hiramatsu A, Fukushima D, et al. Degradation of decorin by matrix metalloproteinases: identification of the cleavage sites, kinetic analyses and transforming growth factor-betal release. Biochem J 1997;322:809-14.

46 Lescaudron L, Peltekian E, Fontaine-Perus J, et al. Blood borne macrophages are essential for the triggering of muscle regeneration following muscle transplant. Neuromuscul Disord 1999:9:72-80.

47 Santavirta S, Konttinen YT, Antti-Poika I, et al. Inflammation of the subacromial bursa in chronic shoulder pain. Arch Orthop Trauma Surg 1992;1 1 1:336-40.

48 Tidball JG. Inflammatory cell response to acute muscle injury. Med Sci Sports Exerc 1995;27:1022-32.

49 Yoshida M, Nakamura T, Kikuchi T, et al. Expression of monocyte chemoattractant protein-1 in primary cultures of rabbit intervertebral disc cells. J Orthop Res 2002;20:1298-304.

50 Marsolais D, Cote CH, Frenette J. Neutrophils and macrophages accumulate sequentially following Achilles tendon injury. J Orthop Res 2001;19:1203-9.

51 Woiciak B, Crossan JF. The accumulation of inflammatory cells in synovial sheath and epitenon during adhesion formation in healing rat flexor tendons. Clin Exp Immunol 1993;93:108-14.

52 Mass DP, Tuel RJ. Intrinsic healing of the laceration site in human superficialis flexor tendons in vitro. J Hand Surg [Am] 1991;16:24-30.

53 Yuan J, Murrell GA, Wei AQ, et al. Apoptosis in rotator cuff tendonopathy. J Orthop Res 2002;20:1372-9.

54 Fishel RS, Barbul A, Beschorner WE, et al. Lymphocyte participation in wound healing. Morphologic assessment using monoclonal antibodies. Ann Surg 1987;206:25-9.

55 Vuk-Pavlovic Z, Rohrbach MS. Induction of interleukin-1-beta release from human monocytes by cotton bract tannin. Int Arch Allergy Appl Immunol 1990;91:394-7.

56 Gillitzer R. Inflammation in human skin: a model to study chemokinemediated leukocyte migration in vivo. J Pathol 2001;194:393-4.

57 Blotnick S, Peoples GE, Freeman MR, et al. T lymphocytes synthesize and export heparin-binding epidermal growth factor-like growth factor and basic fibroblast growth factor, mitogens for vascular cells and fibroblasts: differential production and release by CD4+ and CD8+ T cells. Proc Nat Acad Sci USA 1994;91:2890-4.

58 Barbul A, Shawe T, Rotter SM, et al. Wound healing in nude mice: a study on the regulatory role of lymphocytes in fibroplasia. Surgery 1989; 105:764-9.

59 Efron JE, Frankel HL, Lazarou SA, et al. Wound healing and T-lymphocytes. J Surg Res 1990;48:460-3.

60 Schaffer M, Barbul A. Lymphocyte function in wound healing and following injury. Br J Surg 1998;85:444-60,

60 a Bensadoun E, Burke AK, Hogg JC, Roberts CR. Proteoglycan deposition in pulmonary fibrosis. Am J Respir Crit Care Med 1996;154:1819-28.

61 Bucala R, Spiegel LA, Chesney J, et al. Circulating fibrocytes define a new leukocyte subpopulation that mediates tissue repair. Mol Med 1994; 1:71-81.

6 la Roberts CR. Versican in the cell biology of pulmonary fibrosis. In: Garg H, ed. Proteoglycans in lung disease. New York: Marcel Dekker, 2002.

62 Almekinders LC, Banes AJ, Ballenger CA. Effects of repetitive motion on human fibroblasts. Med Sci Sports Exerc 1993;25:603-7.

63 Wang JH. Paper presented at IOC Workshop on Tendinopathies. Athens, Greece, 2003

64 Banes AJ, Hart DA, Archambault JM. Paper presented at IOC Workshop on Tendinopathies. Athens, Greece, 2003.

65 Kjaer M, Langberg H, Skovgaard D, et al. In vivo studies of peritendinous tissue in exercise. Scand J Med Sci Sports 2000;10:326-31.

66 Schaffer M, Beiter T, Becker HD, et al. Neuropeptides: mediators of inflammation and tissue repair? Arch Surg 1998;133:1107-16.

67 D'Andrea MR, Rogahn CJ, Andrade-Gordon P. Localization of proteaseactivated receptors- 1 and -2 in human mast cells: indications for an amplified mast cell degranulation cascade. Biotech Histochem 2000;75:85-90.

68 Kawabata A, Kawao N, Kuroda R, et al. Peripheral PAR-2 triggers thermal hyperalgesia and nociceptive responses in rats. Neuroreport 2001;12:715-19.

69 Boyce JA. Mast cells: beyond IgE. J Allergy Clin Immunol 2003;1 1:24-32, quiz 33. 
70 Noli C, Miolo A. The mast cell in wound healing. Vet Dermatol 2001;12:303-13.

71 Gordon JR. TGFbetal and TNFalpha secreted by mast cells stimulated via the FcepsilonRI activate fibroblasts for high-level production of monocyte chemoattractant protein-1 (MCP-1). Cell Immunol 2000;201:42-9.

72 Baram D, Vaday GG, Salamon P, et al. Human mast cells release metalloproteinase-9 on contact with activated T cells: juxtacrine regulation by TNF-alpha. J Immunol 2001;167:4008-16.

73 Steiner DR, Gonzalez NC, Wood JG. Mast cells mediate the microvascular inflammatory response to systemic hypoxia. J Appl Physiol 2003;94:325-34.

74 Nguyen M, Solle M, Audoly LP, et al. Receptors and signaling mechanisms required for prostaglandin E2-mediated regulation of mast cell degranulation and IL-6 production. J Immunol 2002;169:4586-93.

75 Nilsson G, Forsberg-Nilsson K, Xiang Z, et al. Human mast cells express functional TrkA and are a source of nerve growth factor. Eur J Immunol 1997; 27:2295-301.

76 Gottwald T, Coerper S, Schaffer M, et al. The mast cell-nerve axis in wound healing: a hypothesis. Wound Repair Regen 1998:6:8-20.

77 Andres KH, von During M, Schmidt RF. Sensory innervation of the Achilles tendon by group III and IV afferent fibers. Anat Embryol (Berl) 1985;172:145-56

78 Mamet J, Baron A, Lazdunski $M$, et al. Proinflammatory mediators, stimulators of sensory neuron excitability via the expression of acid-sensing ion channels. J Neurosci 2002;22:10662-70.

79 Kimpinski K, Mearow K. Neurite growth promotion by nerve growth factor and insulin-like growth factor-1 in cultured adult sensory neurons: role of phosphoinositide 3-kinase and mitogen activated protein kinase. J Neurosci Res 2001:63:486-99.

80 Kakar S, Khan U, McGrouther DA. Differential cellular response within the rabbit tendon unit following tendon injury. J Hand Surg [Br] 1998;23:627-32.

81 Blair RJ, Meng H, Marchese MJ, et al. Human mast cells stimulate vascular tube formation. Tryptase is a novel, potent angiogenic factor. J Clin Invest 1997;99:2691-700

82 Palmgren T, Gronblad M, Virri J, et al. An immunohistochemical study of nerve structures in the anulus fibrosus of human normal lumbar intervertebral discs. Spine 1999:24:2075-9.

83 Palmgren T, Gronblad M, Virri J, et al. Immunohistochemical demonstration of sensory and autonomic nerve terminals in herniated lumbar disc tissue. Spine 1996;21:1301-6

84 Freemont AJ, Jeziorska M, Hoyland JA, et al. Mast cells in the pathogenesis of chronic back pain: a hypothesis. J Pathol 2002;197:281-5.

85 Steinhoff $M$, Vergnolle N, Young SH, et al. Agonists of proteinase-activated receptor 2 induce inflammation by a neurogenic mechanism. Nat Med 2000;6:151-8.

86 Geppetti P. Sensory neuropeptide release by bradykinin: mechanisms and pathophysiological implications. Regul Pept 1993;47:1-23.

87 Bolton TB, Clapp LH. Endothelial-dependent relaxant actions of carbachol and substance P in arterial smooth muscle. Br J Pharmacol 1986;87:713-23.

88 Seegers HC, Hood VC, Kidd BL, et al. Enhancement of angiogenesis by endogenous substance $P$ release and neurokinin- 1 receptors during neurogenic inflammation. J Pharmacol Exp Ther 2003;306:8-12.

89 Baluk P, Bertrand C, Geppetti P, et al. NK1 receptors mediate leukocyte adhesion in neurogenic inflammation in the rat trachea. Am J Physiol 1995;268:L263-9

90 Carolan EJ, Casale TB. Effects of neuropeptides on neutrophil migration through noncellular and endothelial barriers. J Allergy Clin Immunol 1993;92:589-98.

91 Hartung HP, Wolters K, Toyka KV. Substance P: binding properties and studies on cellular responses in guinea pig macrophages. J Immunol 1986;136:3856-63.

92 Payan DG, Goetzl EJ. Modulation of lymphocyte function by sensory neuropeptides. J Immunol 1985; 135:783s-6s.

93 Reynier-Rebuffel AM, Mathiau P, Callebert J, et al. Substance P, calcitonin gene-related peptide, and capsaicin release serotonin from cerebrovascular mast cells. Am J Physiol 1994;267:R1 421-9.

94 Ivie TJ, Bray RC, Salo PT. Denervation impairs healing of the rabbit medial collateral ligament. J Orthop Res 2002;20:990-5.

95 Ackermann PW, Li J, Lundeberg T, et al. Neuronal plasticity in relation to nociception and healing of rat achilles tendon. J Orthop Res 2003;21:432-41.

96 Curl WW. Clinical relevance of sports-induced inflammation. In: Gordon JR ed. Sports-induced inflammation. Park Ridge, IL: American Academy of Orthopaedic Surgeons, 1989:149-54.

97 Almekinders LC. The efficacy of nonsteroidal anti-inflammatory drugs in the treatment of ligament injuries. Sports Med 1990;9:137-42.

98 Alfredson $\mathrm{H}$, Thorsen $\mathrm{K}$, Lorentzon R. In situ microdialysis in tendon tissue: high levels of glutamate, but not prostaglandin E2 in chronic Achilles tendon pain. Knee Surg Sports Traumatol Arthrosc 1999;7:378-81.

99 Alfredson $\mathrm{H}$, Liung $\mathrm{BO}$, Thorsen $\mathrm{K}$, et al. In vivo investigation of ECRB tendons with microdialysis technique: no signs of inflammation but high amounts of glutamate in tennis elbow. Acta Orthop Scand 2000;71:475-9.

100 Alfredson H, Forsgren S, Thorsen K, et al. In vivo microdialysis and immunohistochemical analyses of tendon tissue demonstrated high amounts of free glutamate and glutamate NMDAR1 receptors, but no signs of inflammation, in Jumper's knee. J Orthop Res 2001;19:881-6.

101 Warner TD, Mitchell JA. Cyclooxygenase-3 (COX-3): filling in the gaps toward a COX continuum? Proc Natl Acad Sci USA 2002;99:13371-3.

102 Gajraj NM. Cyclooxygenase-2 inhibitors. Anesth Analg 2003;96:1720-38

103 Berg J, Christoph T, Widerna M, et al. Isoenzyme-specific cyclooxygenase inhibitors: a whole cell assay system using the human erythroleukemic cell line HEL and the human monocytic cell line Mono Mac 6. J Pharmacol Toxicol Methods 1997;37:179-86.
104 Meade EA, Smith WL, DeWitt DL. Differential inhibition of prostaglandin endoperoxide synthase (cyclooxygenase) isozymes by aspirin and other non-steroidal anti-inflammatory drugs. J Biol Chem 1993;268:6610-14

105 Hutchins B, Patel H, Spears R. Attenuation of pro-inflammatory neuropeptide levels produced by a cyclooxygenase- 2 inhibitor in an animal model of chronic temporomandibular joint inflammation. J Orofac Pain 2002;16:312-16.

106 Chandrasekharan NV, Dai H, Roos KL, et al. COX-3, a cyclooxygenase-1 variant inhibited by acetaminophen and other analgesic/antipyretic drugs: cloning, structure, and expression. Proc Natl Acad Sci USA 2002;99:13926-31

107 Dahners LE, Gilbert JA, Lester GE, et al. The effect of a nonsteroidal antiinflammatory drug on the healing of ligaments. Am J Sports Med 1988;16:641-6.

108 Almekinders LC. Anti-inflammatory treatment of muscular injuries in sport. An update of recent studies. Sports Med 1999;28:383-8.

109 Elder CL, Dahners LE, Weinhold PS. A cyclooxygenase-2 inhibitor impairs ligament healing in the rat. Am J Sports Med 2001;29:801-5.

110 Stovitz S, Johnson R. NSAIDs and musculoskeletal treatment: what is the clinical evidence? Phys Sportsmed 2003;31:21-7

111 Fredberg $U$. Local corticosteroid injection in sport: review of literature and guidelines for treatment. Scand J Med Sci Sports 1997:7:131-9.

112 Case JP. Old and new drugs used in rheumatoid arthritis: a historical perspective. Part 1: the older drugs. Am J Ther 2001;8:123-43.

113 MacLeod JN, Fubini SL, Gu DN, et al. Effect of synovitis and corticosteroids on transcription of cartilage matrix proteins. Am J Vet Res 1998;59:1021-6.

114 Snyder DS, Unanue ER. Corticosteroids inhibit murine macrophage la expression and interleukin 1 production. J Immunol 1982;129:1803-5.

115 Supowit SC, Christensen MD, Westlund KN, et al. Dexamethasone and activators of the protein kinase $A$ and $C$ signal transduction pathways regulate neuronal calcitonin gene-related peptide expression and release. Brain Res 1995;686:77-86.

116 Levine WN, Bergfeld JA, Tessendorf W, et al. Intramuscular corticosteroid injection for hamstring injuries. A 13-year experience in the National Football League. Am J Sports Med 2000;28:297-300.

117 Goddard DH, Revell PA, Cason J, et al. Ultrasound has no anti-inflammatory effect. Ann Rheum Dis 1983;42:582-4.

118 Rantanen J, Thorsson O, Wollmer $\mathrm{P}$, et al. Effects of therapeutic ultrasound on the regeneration of skeletal myofibers after experimental muscle injury. Am J Sports Med 1999;27:54-9.

119 Azuma Y, Ito M, Harada Y, et al. Low-intensity pulsed ultrasound accelerates rat femoral fracture healing by acting on the various cellular reactions in the fracture callus. J Bone Miner Res 2001;16:671-80.

120 Ito M. Azuma Y, Ohta T, et al. Effects of ultrasound and 1,25dihydroxyvitamin D3 on growth factor secretion in co-cultures of osteoblasts and endothelial cells. Ultrasound Med Biol 2000;26:161-6.

121 Bjordal JM, Couppe Roberta C, Chow RT, et al. A systematic review of low level laser therapy with location-specific doses for pain from chronic joint disorders. Aust J Physiother 2003;49:107-16.

122 Honmura A, Yanase M, Obata J, et al. Therapeutic effect of Ga-Al-As diode laser irradiation on experimentally induced inflammation in rats. Lasers Surg Med 1992; 12:441-9.

123 Vasseljen O Jr, Hoeg N, Kjeldstad B, et al. Low level laser versus placebo in the treatment of tennis elbow. Scand J Rehabil Med 1992:24:37-42.

124 Stralka SW, Jackson JA, Lewis AR. Treatment of hand and wrist pain. A randomized clinical trial of high voltage pulsed, direct current built into a wrist splint. AAOHN J 1998:46:233-6.

125 Griffin JW, Newsome LS, Stralka SW, et al. Reduction of chronic posttraumatic hand edema: a comparison of high voltage pulsed current, intermittent pneumatic compression, and placebo treatments. Phys Ther 1990;70:279-86.

126 Zizic TM, Hoffman KC, Holt PA, et al. The treatment of osteoarthritis of the knee with pulsed electrical stimulation. J Rheumatol 1995;22:1757-61.

127 Thornton RM, Mendel FC, Fish DR. Effects of electrical stimulation on edema formation in different strains of rats. Phys Ther 1998;78:386-94.

128 Karnes JL, Mendel FC, Fish DR, et al. High-voltage pulsed current: its influence on diameters of histamine-dilated arterioles in hamster cheek pouches. Arch Phys Med Rehabil 1995;76:381-6.

129 Bettany JA, Fish DR, Mendel FC. High-voltage pulsed direct current: effect on edema formation after hyperflexion injury. Arch Phys Med Rehabil 1990;71:677-81.

130 Stauber WT, Smith CA, Miller GR, et al. Recovery from 6 weeks of repeated strain injury to rat soleus muscles. Muscle Nerve 2000;23:1819-25.

131 Hurme T, Kalimo H. Adhesion in skeletal muscle during regeneration. Muscle Nerve 1992;15:482-9.

132 Chan YS, Li Y, Foster W, et al. Antifibrotic effects of suramin in injured skeletal muscle after laceration. J Appl Physiol 2003;95:771-80.

133 Diwan $A D$, Wang $M X$, Jang $D$, ef al. Nitric oxide modulates fracture healing. J Bone Miner Res 2000;15:342-51.

134 Cake MA, Appleyard RC, Read RA, et al. Topical administration of the nitric oxide donor glyceryl trinitrate modifies the structural and biomechanical properties of ovine articular cartilage T. Osteoarthritis Cartilage 2003; 11:872-8

135 Paoloni JA, Appleyard RC, Nelson J, et al. Topical nitric oxide application in the treatment of chronic extensor tendinosis at the elbow: a randomized, double-blinded, placebo-controlled clinical trial. Am J Sports Med 2003;31:915-20.

136 Yuan J, Murrell GA, Wei AQ, et al. Addition of nitric oxide via nitroflurbiprofen enhances the material properties of early healing of young rat Achilles tendons. Inflamm Res 2003;52:230-7. 